\title{
Cytogenetic evaluation of extractable agents from airborne particulate matter generated in the city of Catania (Italy)
}

\author{
Salvatore Motta ${ }^{\mathrm{a}, *}$, Concetta Federico ${ }^{\mathrm{a}}$, Salvatore Saccone ${ }^{\mathrm{a}}$, \\ Vito Librando ${ }^{b}$, Pasquale Mosesso ${ }^{c}$ \\ a Dipartimento di Biologia Animale “M. La Greca”, Universita'di Catania, Via Androne 81, 95124 Catania, Italy \\ b Dipartimento di Chimica, Universita' di Catania, Catania, Italy \\ ${ }^{\mathrm{c}}$ Dipartimento di Agrobiologia e Agrochimica, Universita'degli Studi della Tuscia, Viterbo, Italy
}

Received 4 November 2003; received in revised form 19 February 2004; accepted 19 March 2004

Available online 20 May 2004

\begin{abstract}
In order to document cytogenetic damage associated with air pollution and, possibly, with health effects in the city of Catania, Sicily (Italy), we analyzed the induction of chromosomal aberrations by extractable agents from airborne particulate matter in a Chinese hamster epithelial liver (CHEL) cells. These cells retain their metabolic competence to activate different classes of promutagens/procarcinogens into biologically active metabolites. Airborne particulate matter was obtained from two stationary samplers (stations I and II) in two areas endowed by an elevated car transit in the centre of Catania. The results obtained clearly indicated that airborne particulate matter from both stations I and II proved to be clastogens in CHEL cells but not in Chinese hamster ovary $(\mathrm{CHO})$ cells without metabolic activation, indicating that airborne particulate mixtures need to be metabolically converted before exerting their genotoxic potential.

On the basis of these results we can assert that the test system employed to identify the cytogenetic potential of airborne particulate matter is useful and profitable for environmental control, and helpful to plan specific actions aimed at reducing the hazards derived from exposure to polluted air.
\end{abstract}

(c) 2004 Elsevier B.V. All rights reserved.

Keywords: Airborne genotoxins; Chromosomal aberrations; Metabolic activation; Air pollution and human health

\section{Introduction}

Air pollution is enormously increasing in our cities creating a potential hazard to the environment and human health. The impact of urban air pollution on health has been studied in many cities in the world. A large number of studies showed mutagenic activity of air pollutants in different mutagenicity short-term assays [1-5] or carcinogenic activity in experimen-

\footnotetext{
* Corresponding author.

E-mail address: mottasal@unict.it (S. Motta).
}

tal animals [6,7]. As indicated by epidemiological studies, exposure to high levels of pollution is associated with an increased risk for cancer, especially lung cancer [8-19]. However, genotoxic activities and consequently the potential health risks of urban air pollutants are different between cities, depending on the sources of pollution, temperature, sun irradiation and other climatic parameters. It is therefore important to know the nature and the genetic effects of the air particulate mixtures in specific cities to evaluate its impact on the health of inhabitants. 